\title{
A Randomized Controlled Trial of a Physician-Directed Treatment Program for Low-Income Patients With High Blood Cholesterol: The Southeast Cholesterol Project
}

\author{
Thomas C. Keyserling, MD, MPH; Alice S. Ammerman, DrPH, RD; C. E. Davis, PhD; \\ Mario Chen Mok, MS; Joanne Garrett, PhD; Ross Simpson, Jr, MD, MPH
}

$\rightarrow$

Objective: To assess the effectiveness of a cholesterollowering intervention designed to facilitate the management of hypercholesterolemia by primary care clinicians.

Design: Randomized controlled trial, with randomization of clinician-patient groups.

Setting: Twenty-one community and rural health centers in North Carolina and Virginia.

Participants: Primary care clinicians ( $\mathrm{n}=42,71 \%$ physicians) and the patients they enrolled with high cholesterol $(n=372)$. Twenty-two clinicians were randomized to give the special intervention (184 patients) and 20 to give usual care (188 patients). Two thirds of participating patients were women, $40 \%$ were African American, and $11 \%$ were Native American.

Infervention: A 90-minute tutorial to train clinicians how to use a structured assessment and treatment program (Food for Heart Program) consisting of a brief dietary assessment and three 5- to 10-minute dietary counseling sessions given by the primary care clinician, referral to a local dietitian if the low-density lipoprotein cholesterol (LDL-C) remained elevated at 4-month follow-up, and a prompt for the clinician to consider lipid-lowering medication based on the LDL-C at 7-month follow-up.

Main Oukcome Measures: Changes in total and LDL cholesterol at 4-month follow-up and averaged over a 1-year follow-up period (4-, 7-, and 12-month follow-up).
Results: At 4-month follow-up, total cholesterol decreased $0.33 \mathrm{mmol} / \mathrm{L}(12.6 \mathrm{mg} / \mathrm{dL})$ in the intervention group and $0.21 \mathrm{mmol} / \mathrm{L}(8.3 \mathrm{mg} / \mathrm{dL})$ in the control group: the difference was $0.11 \mathrm{mmol} / \mathrm{L}(4.2 \mathrm{mg} / \mathrm{dL})(90 \%$ confidence interval $[\mathrm{CI}],-0.02$ to $0.24 \mathrm{mmol} / \mathrm{L}[-0.7$ to $9.1 \mathrm{mg} / \mathrm{dL}]$ ). The average reduction during the 1-year follow-up period was $0.09 \mathrm{mmol} / \mathrm{L}(3.6 \mathrm{mg} / \mathrm{dL})$ greater in the intervention group ( $90 \% \mathrm{Cl},-0.01$ to $0.19 \mathrm{mmol} / \mathrm{L}[-0.3$ to $7.5 \mathrm{mg} /$ $\mathrm{dL}]$ ). Eight percent of intervention patients were taking lipid-lowering medication at follow-up visits compared with $15 \%$ of control patients. In a subgroup analysis restricted to the $89 \%$ of returnees who were not taking lipidlowering medication, the reduction in total cholesterol at 4-month follow-up was $0.14 \mathrm{mmol} / \mathrm{L}(5.5 \mathrm{mg} / \mathrm{dL})$ greater in the intervention group ( $95 \% \mathrm{CI}, 0.01$ to $0.28 \mathrm{mmol} / \mathrm{L}$ [0.3 to $10.7 \mathrm{mg} / \mathrm{dL}]$ ); averaged over 1 year, it was 0.14 $\mathrm{mmol} / \mathrm{L}(5.3 \mathrm{mg} / \mathrm{dL})$ greater $(95 \% \mathrm{CI}, 0.03$ to $0.24 \mathrm{mmol} / \mathrm{L}$ [1.2 to $9.4 \mathrm{mg} / \mathrm{dL}$ ]). Changes in LDL-C were similar.

Conclusions: Total cholesterol and LDL-C decreased more in the intervention group than in the control group. Overall, the difference in lipid reduction between groups was modest and of borderline statistical significance; among participants who did not take lipid-lowering medication during follow-up, the difference in lipid reduction between groups was larger. We conclude that primary care clinicians can be trained to give a cholesterollowering intervention to low-income patients that results in modest, short-term reductions in total cholesterol and LDL-C.

Arch Fam Med. 1997;6:135-145
From the Departments of Medicine (Drs Keyserling, Garrett, and Simpson), Nutrition (Dr Ammerman), and Biostatistics (Dr Davis and $\mathrm{Mr}$ Chen Mok), University of North Carolina, Chapel Hill.

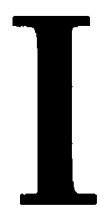

N 1988, the National Cholesterol Education Program (NCEP) published guidelines on the detection, evaluation, and management of high blood cholesterol in adults, emphasizing identification and management of hypercholesterolemic patients by primary care physicians, dietary modification as the foundation of cholesterol reduction, and pharmacotherapy when indicated after a 6-month trial of diet treatment. ${ }^{1}$ According to the guidelines, the Step I diet (total fat $<30 \%$ of energy, saturated fatty acids $<10 \%$ of energy, and cholesterol $<300 \mathrm{mg} / \mathrm{d}$ ) "should be prescribed and explained by the physician and his or her staff." If the minimal goals are not achieved on this diet by 3 months, the patient should progress to the Step II diet,

\section{For editorial comment, see pages 129 and 146}

usually given by a registered dietitian (further reduction in saturated fatty acids to $<7 \%$ of energy and cholesterol $<200$ $\mathrm{mg} / \mathrm{d}$ ). Few data are available on the 


\section{METHODS}

\section{STUDY DESIGN}

Figure I depicts the study design of the Southeast Cholesterol Project. In brief, patients were screened according to the guidelines of the NCEP Adult Treatment Panel $\mathrm{I}^{1}$ and clinician-patient groups were randomized to receive the special intervention or usual care. Participants returned at 4 months, 7 months, 1 year, and 2 years for follow-up lipid determinations. The study protocol was approved by the institutional review board at the University of North Carolina at Chapel Hill, and written informed consent was obtained from each participant.

\section{SUBJECTS}

\section{Clinicians}

Community and rural health centers in central North Carolina and south central Virginia were identified as study sites because they primarily serve low-income and minority patients. Clinicians (physicians, physician assistants, and nurse practitioners) were invited to participate if they provided primary care for adults and worked at least 2 full days per week at a participating site. Clinicians were randomized to the intervention group or the usual-care group approximately 3 months after they began enrolling patients for the study, ensuring that most patients were enrolled before clinicians were randomized.

\section{Patients}

Clinicians were instructed to enroll patients seen during routine office visits who were felt to be candidates for $\mathrm{CHD}$ risk-factor modification. The enrollment goal for each clinician was 10 patients with high cholesterol. Exclusion criteria were age less than 20 or greater than 75 years; high likelihood of starting drug treatment for hypercholesterolemia within 6 months (ie, known severely elevated lowdensity lipoprotein cholesterol [LDL-C]); known triglycerides greater than $4.52 \mathrm{mmol} / \mathrm{L}(>400 \mathrm{mg} / \mathrm{dL})$, chronic medical conditions such that prevention of CHD was not a priority; severe, acute, self-limited medical problems; inability to speak English; pregnancy or lactation; currently taking medication for hyperlipidemia; and current diet treatment for hyperlipidemia (defined as 1 or more counseling sessions with a nutritionist, nurse, or health educator or 2 or more counseling sessions with a primary care clinician during the preceding 6 months). In addition, patients were excluded if they had a diagnosis consistent with secondary hypercholesterolemia, including diabetes mellitus, hypothyroidism, nephrotic syndrome, renal failure, obstructive liver disease, multiple myeloma, lymphoma, macroglobulinemia, or use of progestin or anabolic steroids (women taking postmenopausal estrogens with progestins or oral contraceptives were not excluded).

Sample size was calculated to provide sufficient power for the primary hypothesis, the comparison of total cholesterol reduction between intervention and usual-care groups at 4 months. For a 1 -sided test with $\alpha=.05$ and difference between groups of $0.39 \mathrm{mmol} / \mathrm{L}(15 \mathrm{mg} / \mathrm{dL})$, approximately 20 clinicians and 200 patients were required in each group to achieve power of $80 \% .^{16,17}$

\section{SCREENING PROTOCOL}

Risk factors and blood lipids were assessed to determine eligibility. The following risk factors were recorded by the enrolling clinician: known CHD, male sex, family history of premature CHD, cigarette smoking, hypertension, definite cerebrovascular or occlusive peripheral vascular disease, and obesity. Risk attributed to high-density lipoprotein cholesterol (HDL-C), defined as a level less than 0.91 $\mathrm{mmol} / \mathrm{L}(35 \mathrm{mg} / \mathrm{dL})$, was assessed at the time of the first lipid panel.

The first screening test was a random, nonfasting cholesterol. If the cholesterol was greater than or equal to $6.2 \mathrm{mmol} / \mathrm{L}(240 \mathrm{mg} / \mathrm{dL})$ or in the range of 5.2 to 6.2 $\mathrm{mmol} / \mathrm{L}$ (200-239 $\mathrm{mg} / \mathrm{dL}$ ) with at least 1 risk factor (allowing for the possibility of low HDL-C as the second risk factor), the patient was invited back for a fasting lipid panel. If the average cholesterol from the first 2 tests was greater than or equal to $6.2 \mathrm{mmol} / \mathrm{L}(240 \mathrm{mg} / \mathrm{dL})$ or in the range of 5.2 to $6.2 \mathrm{mmol} / \mathrm{L}(200-239 \mathrm{mg} / \mathrm{dL})$ with 2 or more risk factors or known CHD, the patient was asked to return for a second lipid panel, a thyrotropin (TSH) level, and a fasting blood glucose test. If the TSH was greater than 2 times the upper limit of normal or if the fasting glucose was greater than $11.1 \mathrm{mmol} / \mathrm{L}(200 \mathrm{mg} / \mathrm{dL})$, the patient was excluded. If the difference between the first and second LDL-C levels was greater than $0.8 \mathrm{mmol} / \mathrm{L}$ (30 mg/ $\mathrm{dL}$ ), the patient was asked to return for a third fasting lipid panel. Patients qualified for the treatment component of this study if their average LDL-C was 4.1 $\mathrm{mmol} / \mathrm{L}(160 \mathrm{mg} / \mathrm{dL})$ or more or in the range of 3.4 to $4.1 \mathrm{mmol} / \mathrm{L}(130-159 \mathrm{mg} / \mathrm{dL})$ with 2 or more risk factors or known CHD. About 2 weeks after each blood test, participants were sent letters reporting their total cholesterol level, and their clinicians received the results of all study blood tests. Enrollment was completed during a 1-year period.

\section{SPECIAL INTERVENTION}

The special intervention (Figure 1) consisted of 3 major components paralleling the NCEP recommendations: (1) a clinician-directed dietary component using the Food for Heart Program (FFHP); (2) referral to a local dietitian if LDL-C remained elevated at 4-month follow-up ( $\geq 4.14$ $\mathrm{mmol} / \mathrm{L}[160 \mathrm{mg} / \mathrm{dL}]$ or in the range of $3.36-4.11 \mathrm{mmol} / \mathrm{L}$ [130-159 mg/dL] with 2 or more risk factors or known CHD); and (3) a prompt for the clinician to consider drug treatment based on the LDL-C at 7 -month follow-up $(\geq 4.91 \mathrm{mmol} / \mathrm{L}[190 \mathrm{mg} / \mathrm{dL}]$ or in the range of $4.14-4.89$ $\mathrm{mmol} / \mathrm{L}$ [160-189 $\mathrm{mg} / \mathrm{dL}$ ] with 2 or more risk factors or known CHD). In addition, a quarterly reinforcement mailing with recipes and health tips was sent to all intervention patients after they returned for their 7-month blood test.

\section{Food for Heart Program}

Using a survey previously tested for reliability and validity, we examined the practices of cholesterol management among primary care physicians serving low-income and minority patients. ${ }^{18}$ While the majority of physicians felt that diet treatment is an effective way of lowering cholesterol 
and that it is their responsibility to provide such therapy, most felt ill-prepared to do so, lacked confidence in their ability to help patients achieve meaningful dietary change, and were skeptical that patients would adhere to a cholesterol-lowering diet. They also cited substantial organizational barriers such as limited time and inadequate educational materials, particularly for lower-literacy patients. These findings are supported by a number of other studies concerning primary care physicians and health behavior counseling. ${ }^{12,19-21}$

Based on our survey results and other research findings, we developed the Food for Heart Program, ${ }^{22}$ which consists of the following components: (1) The dietary risk assessment (DRA), a validated food-frequency instrument that identifies major sources of saturated fat and cholesterol in the diet of low-socioeconomic Southern patients ${ }^{23}$ and is designed to focus and guide tailored counseling. The DRA is a food-based rather than a nutrient-based assessment instrument, includes 31 food or preparation practice items, takes 10 minutes to complete, and requires no nutrition training to administer or interpret. Using a calculated cholesterolsaturated fat index, ${ }^{24}$ which rates the atherogenicity of individual foods, weekly consumption frequencies for each food or preparation practice are classified as "doing well," "needs work," or "problem." Frequencies are aligned in shaded columns under these 3 headings and are scored as 0,1 , and 2 points, reflecting increasing levels of saturated fat and/or cholesterol content. Possible scores range from 0 to 98. (2) A color- and number-coded educational strategy that guides clinician counseling without requiring extensive knowledge of behavior-change theory or food composition. (3) Easy-to-read, illustrated patient education materials that are culturally specific to the population served, promote interaction between patient and clinician, divide recommendations into small achievable steps, and offer practical assistance for dietary change. (4) A mechanism for the clinician to easily record goals and monitor patient progress.

\section{Dietitian Referral}

If the LDL-C remained elevated at 4 months, participants were referred to a dietitian or health educator for a maximum of 3 counseling sessions, each lasting 30 minutes. In some instances, dietitians or health educators were available at the patient's health center, but in most cases they were identified from local health departments, hospital outpatient services, or the agricultural extension service. They were trained to use the FFHP educational materials in greater depth and to supplement this program with other materials as appropriate. At the end of 3 counseling sessions, the dietitians or health educators completed a summary checklist that was mailed to the clinic and filed in the patient's FFHP folder. This checklist served as feedback to the clinician and as a guide for long-term monitoring and reinforcement at subsequent clinic visits.

\section{Prompt for Use of Lipid-Lowering Medication}

The prompt consisted of a letter for the clinician and a drug treatment folder for the patient's chart. The folder included a quick overview of NCEP guidelines for initiating drug therapy, including medications of choice and their cost, detailed information on each class of lipid-lowering agents and a flow diagram illustrating how to use the agents, and simply written, single-page handouts for the patient describing the importance of each medication, getting started, increasing the dosage, coping with potential adverse effects, and other information designed to help maximize adherence to the medical regimen.

A nutritionist on the study staff trained intervention clinicians to use the FFHP during a 90-minute tutorial that included a brief review of essential elements of a lipidlowering diet, dietary behavior-change strategies, effective use of the FFHP materials, and practice using the materials. The study staff facilitated referral to a nutritionist, prompted clinicians to consider use of lipid-lowering medications when indicated, and mailed reinforcement pamphlets to intervention patients. Usual-care clinicians were advised to manage their patients' hypercholesterolemia according to their usual practices.

\section{DATA COLLECTION}

Phlebotomy was performed at participating clinics. Prior to phlebotomy for lipid panels, fasting status was assessed. During screening, if a patient was not fasting, he or she was asked to return after a 10-hour fast. For follow-up testing, fasting was recommended but not required. At each follow-up blood test, use of lipid-lowering medication was assessed.

Blood was collected into a serum separator tube, allowed to clot, and centrifuged, and the serum was transferred to a storage vial, which was cooled to and maintained at approximately $4^{\circ} \mathrm{C}$ until analysis. On a weekly basis, specimens were transported to the University of North Carolina Hospitals laboratory, a participant in the Centers for Disease Control and Prevention lipid standardization program. Cholesterol and triglycerides were determined by automated enzymatic methods. The HDL-C was determined after precipitation with dextran sulfate- $\mathrm{Mg}^{2+} \cdot{ }^{25}$ If the triglycerides were less than or equal to $4.52 \mathrm{mmol} / \mathrm{L}(400 \mathrm{mg} /$ dL) and the participant reported fasting status, LDL-C was calculated using the Friedewald formula. ${ }^{26}$

Dietary change was measured using the DRA, where a higher score is associated with a higher intake of saturated fat and cholesterol. Food items for the DRA were selected based on National Health and Nutrition Examination Survey (NHANES) data identifying specific foods that contribute most to the intake of saturated fat in the diet of African Americans. ${ }^{23}$ In a prior validation study, we compared DRA scores with Keys scores ${ }^{27}$ (representing the atherogenic potential of the diet) calculated from 72 hours of dietary recall data in a low-income, largely minority patient population. We found a significant correlation between the Keys and DRA scores $(r=0.60 ; P<.001)$, and negative associations between the DRA score and both dietary fiber $(r=-0.57 ; P<.001)$ and percent of energy from carbohydrates $(r=-0.45 ; P<.01){ }^{23}$ The DRA was administered at baseline and at 4-month and 1-year follow-up.

Baseline questionnaires were completed by clinic staff; follow-up questionnaires were completed by trained telephone interviewers blinded to the patient's study group. The clinic chart of participants was abstracted by trained reviewers from the date of treatment assignment to the date of the 4-month follow-up blood test to assess providers' use

Continued on next page 
of the FFHP materials, number of routine office visits, type and amount of dietary advice provided by usual-care clinicians, and major medical problems diagnosed during this period. Vital status was assessed by chart audit and telephone follow-up.

\section{STATISTICAL METHODS}

Baseline characteristics of clinicians were compared by the 2 -sample $t$ test for means and $\chi^{2}$ test for dichotomous variables. Baseline patient characteristics were compared using the same tests, but with adjustment for randomization by clinician ${ }^{28}$ using Stata software. ${ }^{29}$ All outcome comparisons between study groups controlled for randomization by clinician.

The primary hypothesis of this study was that the intervention would result in greater reduction of total and LDL cholesterol than usual care at 4 months of follow-up. A major secondary hypothesis was that the average reduction of total and LDL cholesterol during the 1-year follow-up period would be greater for the intervention group. To conform with these hypotheses, 1-sided tests were used for the comparisons, and 90\% confidence intervals (CIs) are reported. For all other comparisons, including the comparisons of lipid change for the subgroup not taking lipidlowering medication, 2 -sided $P$ values and/or $95 \%$ CIs are reported.

Differences in lipid change between groups from baseline (average of lipid determinations during screening) to 4 months, 7 months, and 1 year and the average difference through 1 year of follow-up were assessed with a mixed model ${ }^{30}$ using SAS software. ${ }^{31}$ The model included random effects to account for the correlation among patients within clinician and between measurements ( 4 months, 7 months, and l year) within patient. The treatment effect was included as a fixed effect. To adjust the treatment comparison between groups, a set of variables was also included in the model as fixed effects. This set included baseline characteristics deemed relevant to lipid change a priori (age, sex, race, baseline lipid level, educational achievement, smoking, known CHD, and marital status) and relevant variables from the chart audit, including the total number of routine visits with clinicians and diet counseling at these visits. Statistical tests for changes in triglyceride level were performed on log-transformed data. Differences in dietary assessment change score from baseline to follow-up were also assessed with a mixed model, controlling for the same set of variables as noted for blood lipids. Differences in lipids and dietary change score averaged over 2 or more time periods are presented only if the treatment by time interaction term was not significant.

Our primary analysis of lipid change includes all returnees for follow-up lipid tests whether or not they reported taking lipid-lowering medication. We also conducted an intention-to-treat analysis, setting the lipid change value to 0 for participants who did not return for follow-up blood work at 4 months and 1 year (if a patient did not return at 7 months, we imputed a value as the average of 4 months and 1 year). Finally, to assess lipid change not attributable to use of lipid-lowering medication, a parallel analysis was done for participants who returned and were not taking such medications. effectiveness of these recommendations at lowering blood lipids when implemented in routine practice settings. Of special interest is the impact of such guidelines on lowincome and minority patients, who are at highest risk for coronary heart disease (CHD) $)^{2,3}$ and perhaps least likely to benefit from health promotion programs targeted to others.

Because low-income and minority Americans have frequent contact with physicians, ${ }^{4}$ the NCEP recommendation that primary care physicians initiate diet counseling and monitor diet and lipid changes is appropriate for these groups of patients. However, there are many barriers to implementation of these guidelines by physicians, especially for low-income patients. First, physicians receive little training in nutrition or behaviorchange counseling, ${ }^{5,6}$ and although national surveys indicate that physicians are becoming more convinced of the benefit of lipid-lowering interventions, ${ }^{7}$ most physicians still report minimal diet counseling activity. ${ }^{89} \mathrm{Sec}-$ ond, existing nutrition education materials are designed primarily for well-educated, nonminority populations. ${ }^{10}$ Third, nutrition referral services for chronic disease prevention are limited because they are rarely covered by insurance, Medicaid, or Medicare, and the majority of public health nutritionists who would provide such services are funded primarily for maternal and child health services. ${ }^{\text {II }}$

Effective and practical physician-based interventions for the reduction of blood cholesterol are needed.
Such interventions should recognize and address the obstacles to successful counseling faced by busy primary care clinicians. ${ }^{12-15}$ In this article, we report results through 1-year follow-up of a cholesterol-lowering intervention that is based on the NCEP treatment recommendations and designed to circumvent many of the obstacles faced by primary care physicians in reducing serum cholesterol among low-income and minority patients.

RESULTS

\section{BASELINE CHARACTERISTICS-CLINICIANS AND PATIENTS}

Forty-nine clinicians at 21 community and rural health centers enrolled 999 patients into the screening component of this study. Of these, 828 (83\%) completed all requested screening blood tests and 372 (37\%) had high blood cholesterol as defined in the screening protocol and participated in the treatment component of this study. Of the 49 clinicians, 22 were randomized to give the special intervention, 20 to give usual care, and 7 were not randomized ( 1 did not enroll patients and 6 resigned, went on leave, or withdrew from the study before randomization). The mean age of participating clinicians was 36 years, $60 \%$ were male, $81 \%$ were white, and $71 \%$ were physicians. There were no statistically significant differences between intervention and usual-care clinicians in baseline variables. 


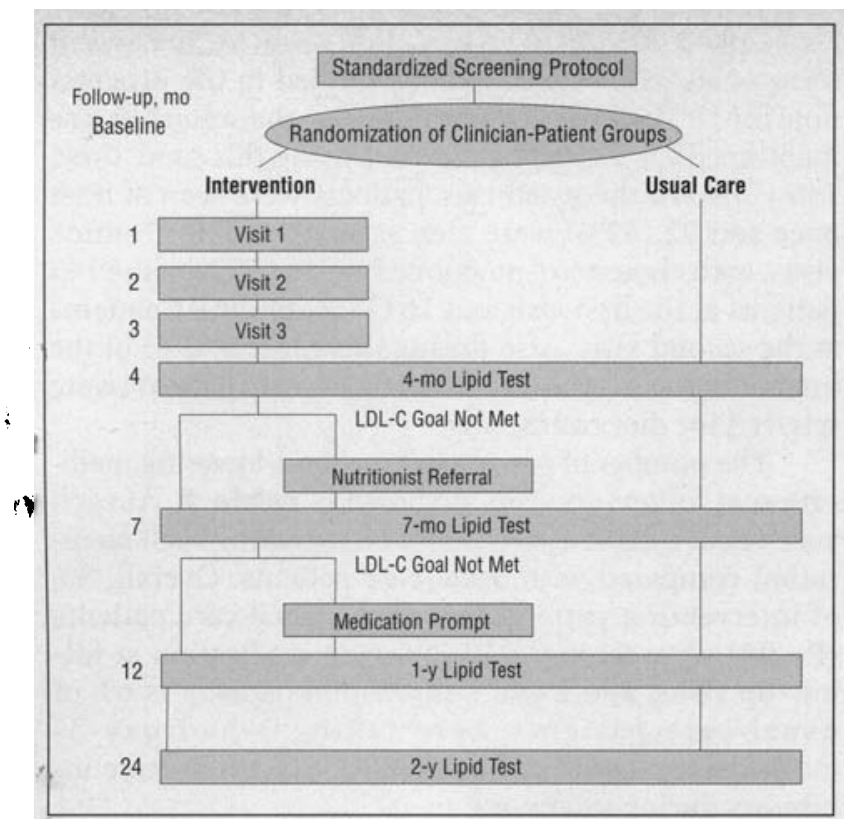

Figure 1. Flow diagram of study. LDL-C indicates low-density lipoprotein cholesterol.

Patients were assigned to intervention $(n=184)$ or usual care $(\mathrm{n}=188)$ according to the treatment assignment of their clinician. Intervention patients were about 3 years older and more likely female than usual-care patients (Table 1). There were no differences in racial composition between groups, with about half of both groups nonwhite: $39 \%$ of intervention patients were African American and $11 \%$ native American, and $40 \%$ of usualcare patients were African American and 12\% Native American. Self-reported educational achievement was low, with $48 \%$ of patients in both groups reporting less than a high school education.

Participants were at high risk for CHD: $60 \%$ were hypertensive, $27 \%$ reported a positive family history for CHD, and 23\% were obese. Most participants reported having their cholesterol checked prior to enrollment and, at the time of enrollment, about two thirds were trying to lower their cholesterol by dietary modification. There were no differences between groups in baseline DRA score or baseline lipids.

\section{SPECIAL INTERVENTION VISITS}

One hundred seventy-nine intervention patients (97\%) returned for their first intervention treatment visit, 178 (97\%) for the second, and 175 (95\%) for the third. Intervention clinicians were instructed to select 2 dietary goals at each visit and mark these on both the DRA and the patient tip sheet. Charts were reviewed to assess the degree to which clinicians followed these instructions. Dietary change goals were checked on the DRA for $78 \%$, $72 \%$, and $65 \%$ of the patients at visits 1,2 , and 3 , respectively, and tip sheets were given out to $98 \%, 94 \%$, and $89 \%$ of patients at visits 1,2 , and 3 , respectively.

of 170 intervention patients who returned for the 4-month follow-up blood test, 140 met NCEP criteria for referral to a dietitian and were referred. Of these, 108 (77\%) attended 1 visit with a dietitian or health educa-
Table 1. Baseline Patient Characteristics*

\begin{tabular}{|c|c|c|c|}
\hline Characteristic & $\begin{array}{c}\text { Special } \\
\text { Intervention } \\
(n=184)\end{array}$ & $\begin{array}{l}\text { Usual Care } \\
(n=188)\end{array}$ & $P$ \\
\hline \multicolumn{4}{|l|}{ Demographics } \\
\hline Age, y & 57.6 & 54.2 & .02 \\
\hline Female, \% & 77 & 57 & .001 \\
\hline White, $\%$ & 50 & 47 & .76 \\
\hline Education, mean grade & 10.5 & 10.8 & .59 \\
\hline Living with spouse, $\%$ & 58 & 61 & .61 \\
\hline $\begin{array}{l}\text { Average No. of adults } \\
\text { in household }\end{array}$ & 2.2 & 2.1 & .79 \\
\hline Employed full-time, \% & 32 & 41 & .13 \\
\hline \multicolumn{4}{|l|}{$\mathrm{CHD}$ risk factors } \\
\hline Known $\mathrm{CHD}, \%$ & 10 & 10 & .94 \\
\hline Family history of $\mathrm{CHD}, \%$ & 29 & 26 & .58 \\
\hline Smokers, \% & 22 & 15 & .09 \\
\hline History of hypertension, \% & 64 & 57 & .31 \\
\hline $\begin{array}{l}\text { History of cerebrovascular } \\
\text { or peripheral vascular } \\
\text { disease, \% }\end{array}$ & 7 & 5 & .62 \\
\hline Obese per clinician, \% & 22 & 25 & .47 \\
\hline $\begin{array}{l}\mathrm{HDL}-\mathrm{C}<0.91 \mathrm{mmol} / \mathrm{L} \\
(<35 \mathrm{mg} / \mathrm{dL}), \%\end{array}$ & 18 & 22 & .50 \\
\hline Total No. of risk & & & \\
\hline $\begin{array}{l}\text { factors } \\
\text { Lipid determination/diet } \\
\text { changes prior to } \\
\text { enrollment, } \%\end{array}$ & 1.8 & 1.9 & .53 \\
\hline $\begin{array}{l}\text { Prior cholesterol blood } \\
\text { test }\end{array}$ & 85 & 88 & .57 \\
\hline $\begin{array}{l}\text { Known high } \\
\text { cholesterol }\end{array}$ & 68 & 76 & .18 \\
\hline $\begin{array}{l}\text { Told by MD to lower } \\
\text { cholesterol }\end{array}$ & 63 & 72 & .11 \\
\hline $\begin{array}{l}\text { Trying to lower } \\
\text { cholesterol }\end{array}$ & 67 & 64 & .71 \\
\hline $\begin{array}{l}\text { Dietary assessment and blood } \\
\text { lipids, } \mathrm{mmol} / \mathrm{L}(\mathrm{mg} / \mathrm{dL})\end{array}$ & & & \\
\hline Mean DRA score & 22.0 & 22.0 & .98 \\
\hline Total cholesterol & $6.64(256.6)$ & $6.53(252.7)$ & .18 \\
\hline HDL-C & $1.16(44.9)$ & $1.12(43.4)$ & .23 \\
\hline Triglycerides & $1.59(141.2)$ & $1.64(145.5)$ & .50 \\
\hline LDL-C & $4.71(182.3)$ & $4.62(178.6)$ & .20 \\
\hline
\end{tabular}

*CHD indicates coronary heart disease; $H D L-C$, high-density lipoprotein cholesterol; MD, medical doctor; DRA, dietary risk assessment; and $L D L-C$, low-density lipoprotein cholesterol.

tor, $95(68 \%)$ attended 2 visits, and $87(62 \%)$ attended 3 visits. Sixty-five ( $45 \%$ ) of the 143 intervention patients who returned for their 7-month blood test met NCEP criteria for lipid-lowering medication. These patients' primary care clinicians received a prompt to consider use of such medication.

\section{ROUTINE CARE VISITS AND USE OF LIPID-LOWERING MEDICATION}

In an effort to assess diet counseling practices of clinicians in the 2 treatment groups, counseling behaviors during routine care visits (those not scheduled by the study) were assessed by chart audit. Because intervention clinicians were encouraged to address routine medical concerns along with giving diet counseling at intervention visits, we anticipated that during the first 4 months of follow-up, intervention patients would return for fewer 
routine visits than usual-care patients. During the first 4 months of the study, $96(52 \%)$ of the intervention patients were seen by a clinician at least once and $48(26 \%)$ were seen at least twice for routine office visits, over and

\begin{tabular}{|c|c|c|}
\hline \multirow[b]{2}{*}{ Time } & \multicolumn{2}{|c|}{ Treatment Group, №. (\%) of Patients } \\
\hline & Special Intervention & Usual Care \\
\hline \multicolumn{3}{|l|}{$4 \mathrm{mo}$} \\
\hline Any medication & $6(3)$ & $17(9)$ \\
\hline $\mathrm{HMG}-\mathrm{CO}_{0}{ }^{\star}$ inhibitor & $2(1)$ & $8(4)$ \\
\hline \multicolumn{3}{|l|}{$7 \mathrm{mo}$} \\
\hline Any medication & $10(7)$ & $23(15)$ \\
\hline HMG-COA inhibitor & $1(1)$ & $8(5)$ \\
\hline \multicolumn{3}{|l|}{$1 \mathrm{y}$} \\
\hline Any medication & $23(14)$ & $34(19)$ \\
\hline HMG-COA inhibitor & $5(3)$ & $13(7)$ \\
\hline
\end{tabular}

*HMG-COA indicates 3-hydroxy-3-methylglutaryl-coenzyme A. above the 3 scheduled intervention visits. At the first of these visits, cholesterol was mentioned in the progress note for 10 (10\%) of the 96 patients; at the second, it was mentioned for $3(6 \%)$ of the 48 . During this same time, $145(77 \%)$ of the usual-care patients were seen at least once and 92 (49\%) were seen at least twice for routine visits, with cholesterol mentioned for 44 (30\%) of the 145 patients at the first visit and $16(17 \%)$ of the 92 patients at the second visit. Also during this time, $3(2 \%)$ of the intervention and $16(9 \%)$ of the usual-care patients were referred for diet counseling.

The number of patients taking lipid-lowering medication at follow-up visits is shown is Table 2. At each visit, fewer intervention patients were taking such medication compared with usual-care patients. Overall, $8 \%$ of intervention patients vs $15 \%$ of usual-care patients $(P=.05)$ were taking lipid-lowering medication at follow-up visits, and $2 \%$ of intervention patients vs $6 \%$ of usual-care patients were taking 3-hydroxy-3methylglutaryl-coenzyme A (HMG-CoA) reductase inhibitors during follow-up.

Table 3. Reduction in Adjusted Mean Values for Total Cholesterol and LDL-C From Baseline and Comparison of Change Between Groups*

\begin{tabular}{|c|c|c|c|c|c|c|c|}
\hline \multirow[b]{3}{*}{ Component } & \multicolumn{6}{|c|}{ Change From Baseline, mmol/L [mg/dL] } & \multirow[b]{3}{*}{$\begin{array}{c}\text { Difference } \\
\text { Between Groupst }\end{array}$} \\
\hline & \multicolumn{3}{|c|}{ Intervention } & \multicolumn{3}{|c|}{ Usual Care } & \\
\hline & $\begin{array}{l}\text { No. of } \\
\text { Patients }\end{array}$ & Mean (SE) & $95 \% \mathrm{Cl}$ & $\begin{array}{l}\text { No. of } \\
\text { Patients }\end{array}$ & Mean (SE) & $95 \% \mathrm{Cl}$ & \\
\hline \multicolumn{8}{|c|}{ All Returnees } \\
\hline \\
\hline $4 \mathrm{mo}$ & 170 & $\begin{array}{c}0.33(0.05) \\
{[12.6(2.07)]}\end{array}$ & $\begin{array}{l}0.22 \text { to } 0.43 \\
{[8.5 \text { to } 16.6]}\end{array}$ & 180 & $\begin{array}{l}0.21(0.05) \\
{[8.3(2.02)]}\end{array}$ & $\begin{array}{l}0.11 \text { to } 0.32 \\
{[4.4 \text { to } 12.3 \text { ] }}\end{array}$ & $\begin{array}{l}0.11(-0.02 \text { to } 0.24) \\
{[4.2(-0.7 \text { to } 9.1)]}\end{array}$ \\
\hline $7 \mathrm{mo}$ & 143 & $\begin{array}{c}0.33(0.06) \\
{[12.6(2.22)]}\end{array}$ & $\begin{array}{l}0.21 \text { to } 0.44 \\
{[8.2 \text { to } 16.9]}\end{array}$ & 150 & $\begin{array}{l}0.20(0.06) \\
{[7.6(2.16)]}\end{array}$ & $\begin{array}{l}0.09 \text { to } 0.31 \\
{[3.3 \text { to } 11.8]}\end{array}$ & $\begin{array}{l}0.13(-0.01 \text { to } 0.27) \\
{[5.0(-0.2 \text { to } 10.3)]}\end{array}$ \\
\hline $1 \mathrm{y}$ & 165 & $\begin{array}{l}0.25(0.05) \\
{[9.6(2.09)]}\end{array}$ & $\begin{array}{l}0.14 \text { to } 0.35 \\
{[5.5 \text { to } 13.7]}\end{array}$ & 176 & $\begin{array}{l}0.21(0.05) \\
{[8.0(2.03)]}\end{array}$ & $\begin{array}{l}0.10 \text { to } 0.31 \\
{[4.0 \text { to } 12.0]}\end{array}$ & $\begin{array}{l}0.04(-0.09 \text { to } 0.17) \\
{[1.6(-3.3 \text { to } 6.6)]}\end{array}$ \\
\hline \multicolumn{8}{|l|}{ LDL-C } \\
\hline $4 \mathrm{mo}$ & 164 & $\begin{array}{c}0.33(0.06) \\
{[12.8(2.13)]}\end{array}$ & $\begin{array}{l}0.22 \text { to } 0.44 \\
{[8.6 \text { to } 16.9]}\end{array}$ & 176 & $\begin{array}{l}0.22(0.05) \\
{[8.4(2.07)]}\end{array}$ & $\begin{array}{l}0.11 \text { to } 0.32 \\
{[4.3 \text { to } 12.5]}\end{array}$ & $\begin{array}{l}0.11(-0.02 \text { to } 0.24) \\
{[4.3(-0.7 \text { to } 9.4)]}\end{array}$ \\
\hline $7 \mathrm{mo}$ & 135 & $\begin{array}{c}0.32(0.06) \\
{[12.4(2.28)]}\end{array}$ & $\begin{array}{l}0.20 \text { to } 0.44 \\
{[7.9 \text { to } 16.9]}\end{array}$ & 145 & $\begin{array}{l}0.19(0.06) \\
{[7.4(2.21)]}\end{array}$ & $\begin{array}{l}0.08 \text { to } 0.31 \\
{[3.1 \text { to } 11.8 \text { ] }}\end{array}$ & $\begin{array}{l}0.13(-0.01 \text { to } 0.27) \\
{[5.0(-0.4 \text { to } 10.3)]}\end{array}$ \\
\hline $1 y$ & 153 & $\begin{array}{l}0.24(0.06) \\
{[9.2(2.18)]}\end{array}$ & $\begin{array}{l}0.13 \text { to } 0.35 \\
{[4.9 \text { to } 13.4]}\end{array}$ & 164 & $\begin{array}{l}0.19(0.05) \\
{[7.5(2.12)]}\end{array}$ & $\begin{array}{l}0.09 \text { to } 0.30 \\
{[3.3 \text { to } 11.7]}\end{array}$ & $\begin{array}{l}0.04(-0.09 \text { to } 0.18) \\
{[1.7(-3.5 \text { to } 6.8)]}\end{array}$ \\
\hline \multicolumn{8}{|c|}{ Returnees Not Taking Lipid-Lowering Medication } \\
\hline Total cholesterol & & & & & & & \\
\hline $4 \mathrm{mo}$ & 164 & $\begin{array}{l}0.28(0.05) \\
{[10.9(1.82)]}\end{array}$ & $\begin{array}{l}0.19 \text { to } 0.37 \\
{[7.4 \text { to } 14.5]}\end{array}$ & 163 & $\begin{array}{l}0.14(0.05) \\
{[5.5(1.83)]}\end{array}$ & $\begin{array}{l}0.05 \text { to } 0.23 \\
{[1.9 \text { to } 9.0]}\end{array}$ & $\begin{array}{l}0.14(0.01 \text { to } 0.28) \\
{[5.5(0.3 \text { to } 10.7)]}\end{array}$ \\
\hline $7 \mathrm{mo}$ & 133 & $\begin{array}{c}0.27(0.05) \\
{[10.5(1.99)]}\end{array}$ & $\begin{array}{l}0.17 \text { to } 0.37 \\
{[6.6 \text { to } 14.4]}\end{array}$ & 127 & $\begin{array}{l}0.09(0.05) \\
{[3.5(2.03)]}\end{array}$ & $\begin{array}{l}-0.01 \text { to } 0.19 \\
{[-0.5 \text { to } 7.5]}\end{array}$ & $\begin{array}{l}0.18(0.03 \text { to } 0.33) \\
{[7.0(1.3 \text { to } 12.7)]}\end{array}$ \\
\hline $1 \mathrm{y}$ & 142 & $\begin{array}{l}0.14(0.05) \\
{[5.4(1.93)]}\end{array}$ & $\begin{array}{l}0.04 \text { to } 0.24 \\
{[1.6 \text { to } 9.2]}\end{array}$ & 142 & $\begin{array}{l}0.05(0.05) \\
{[2.1(1.93)]}\end{array}$ & $\begin{array}{l}-0.04 \text { to } 0.15 \\
{[-1.7 \text { to } 5.9]}\end{array}$ & $\begin{array}{l}0.09(-0.05 \text { to } 0.23) \\
{[3.4(-2.1 \text { to } 8.9)]}\end{array}$ \\
\hline \multicolumn{8}{|l|}{ LDL-C } \\
\hline $4 \mathrm{mo}$ & 158 & $\begin{array}{c}0.29(0.05) \\
{[11.2(1.85)]}\end{array}$ & $\begin{array}{l}0.19 \text { to } 0.38 \\
{[7.5 \text { to } 14.8]}\end{array}$ & 160 & $\begin{array}{l}0.17(0.05) \\
{[6.5(1.85)]}\end{array}$ & $\begin{array}{l}0.07 \text { to } 0.26 \\
{[2.9 \text { to } 10.1]}\end{array}$ & $\begin{array}{l}0.12(-0.02 \text { to } 0.26) \\
{[4.6(-0.7 \text { to } 9.9)}\end{array}$ \\
\hline $7 \mathrm{mo}$ & 125 & $\begin{array}{c}0.26(0.05) \\
{[10.2(2.02)]}\end{array}$ & $\begin{array}{l}0.16 \text { to } 0.37 \\
{[6.2 \text { to } 14.2]}\end{array}$ & 122 & $\begin{array}{l}0.09(0.05) \\
{[3.6(2.05)]}\end{array}$ & $\begin{array}{l}-0.01 \text { to } 0.20 \\
{[-0.4 \text { to } 7.6]}\end{array}$ & $\begin{array}{l}0.17(0.02 \text { to } 0.32) \\
{[6.6(0.8 \text { to } 12.4)]}\end{array}$ \\
\hline $1 y$ & 133 & $\begin{array}{l}0.14(0.05) \\
{[5.4(1.97)]}\end{array}$ & $\begin{array}{l}0.04 \text { to } 0.24 \\
{[1.5 \text { to } 9.3]}\end{array}$ & 133 & $\begin{array}{l}0.02(0.05) \\
{[0.7(1.97)]}\end{array}$ & $\begin{array}{l}-0.08 \text { to } 0.12 \\
{[-3.2 \text { to } 4.6]}\end{array}$ & $\begin{array}{l}0.12(-0.02 \text { to } 0.27) \\
{[4.7(-0.9 \text { to } 10.3)]}\end{array}$ \\
\hline
\end{tabular}

*Adjusted for following variables: age, sex, race, baseline lipid level, educational achievement, smoking, known coronary heart disease, marital status, total number of routine visits with clinicians, and diet counseling at these visits. LDL-C indicates low-density lipoprotein cholesterol; and Cl, confidence interval. $\dagger$ The difference between groups is expressed as the mean $(90 \% \mathrm{Cl}$ ) for all returnees and mean $(95 \% \mathrm{Cl})$ for returnees not taking lipid-lowering medications. 


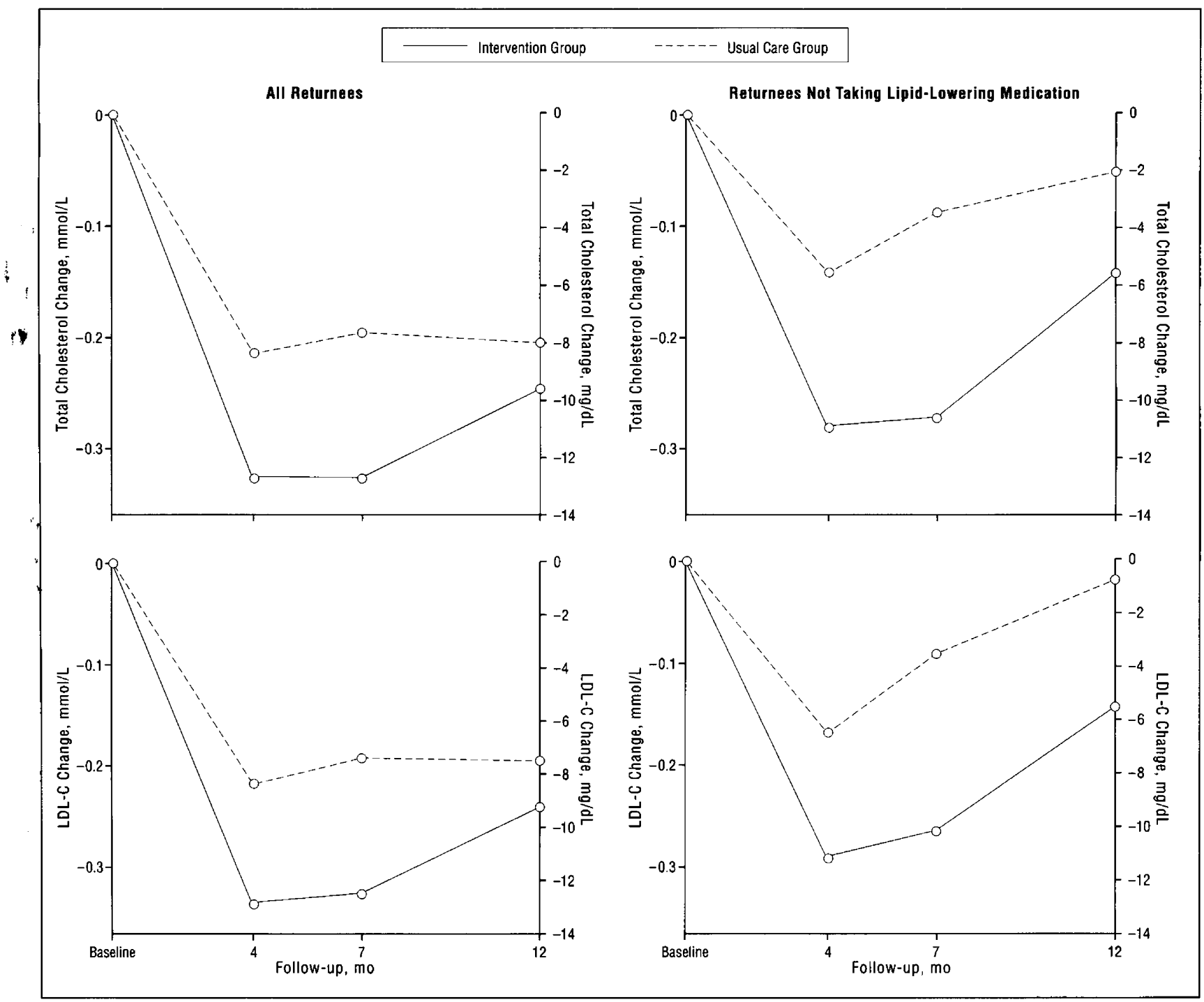

Figure 2. Adjusted mean changes from baseline in total cholesterol and low-density lipoprotein cholesterol (LDL-C).

\section{CHANGES IN BLOOD LIPIDS AND DIETARY ASSESSMENT SCORE}

The return rate for follow-up blood work was $94 \%$ at 4 months, $79 \%$ at 7 months, and $92 \%$ at 1 year. During the follow-up period, total and LDL cholesterol decreased in both treatment groups (Table 3 and Figure 2). For total cholesterol, the reduction for all returnees at 4 months was $5 \%$ for intervention patients and 3\% for usual-care patients; at 1 year, it was $4 \%$ for intervention patients and $3 \%$ for usual-care patients. For LDL-C, the reduction at 4 months was $7 \%$ for intervention and $5 \%$ for usual care; at 1 year, the reductions were $5 \%$ and $4 \%$, respectively.

For our primary outcome, the difference in total cholesterol reduction between groups at 4-month follow-up (Table 3 and Figure 2), there was a 0.11 $\mathrm{mmol} / \mathrm{L}(4.2-\mathrm{mg} / \mathrm{dL})$ greater reduction in the intervention group $(90 \% \mathrm{CI},-0.02$ to $0.24 \mathrm{mmol} / \mathrm{L}$ [ -0.7 to $9.1 \mathrm{mg} /$ dL]) $(P=.08)$. Averaged over the l-year follow-up period, the reduction in the intervention group was 0.09 $\mathrm{mmol} / \mathrm{L}(3.6 \mathrm{mg} / \mathrm{dL})$ greater than for usual care $(90 \% \mathrm{CI}$, -0.01 to $0.19 \mathrm{mmol} / \mathrm{L}[-0.3$ to $7.5 \mathrm{mg} / \mathrm{dL}])(P=.06)$. The results were similar when analyzed with lipid change set to 0 for participants who did not return for follow-up testing (intention to treat). At 4 months, the treatment difference for total cholesterol was $0.09 \mathrm{mmol} / \mathrm{L}(3.5 \mathrm{mg} /$ dL) $(90 \% \mathrm{CI},-0.03$ to $0.21 \mathrm{mmol} / \mathrm{L}[-1.1$ to $8.1 \mathrm{mg} /$ dL]) $(P=.11)$; averaged over the 1-year follow-up period, the difference was $0.08 \mathrm{mmol} / \mathrm{L}(3.0 \mathrm{mg} / \mathrm{dL})(90 \% \mathrm{CI}$, -0.02 to $0.17 \mathrm{mmol} / \mathrm{L}[-0.7$ to $6.7 \mathrm{mg} / \mathrm{dL}])(P=.09)$. The difference in LDL-C change between groups was similar to that for total cholesterol. For all returnees, the average reduction of LDL-C during the 1-year follow-up pe- . riod was $0.10 \mathrm{mmol} / \mathrm{L}(3.7 \mathrm{mg} / \mathrm{dL})$ greater in the intervention group $(90 \% \mathrm{CI},-0.01$ to $0.20 \mathrm{mmol} / \mathrm{L}[-0.5$ to $7.8 \mathrm{mg} / \mathrm{dL}])(P=.08)$. Figure 3 depicts the changes in triglycerides and HDL-C from baseline to follow-up. For these lipids, the differences between groups were small and not significant.

When the analysis was restricted to returnees who were not taking lipid-lowering medications during follow-up (Table 3 and Figure 2), the difference in total and LDL cholesterol reduction between groups increased. For total cholesterol, the treatment difference at 4 months 


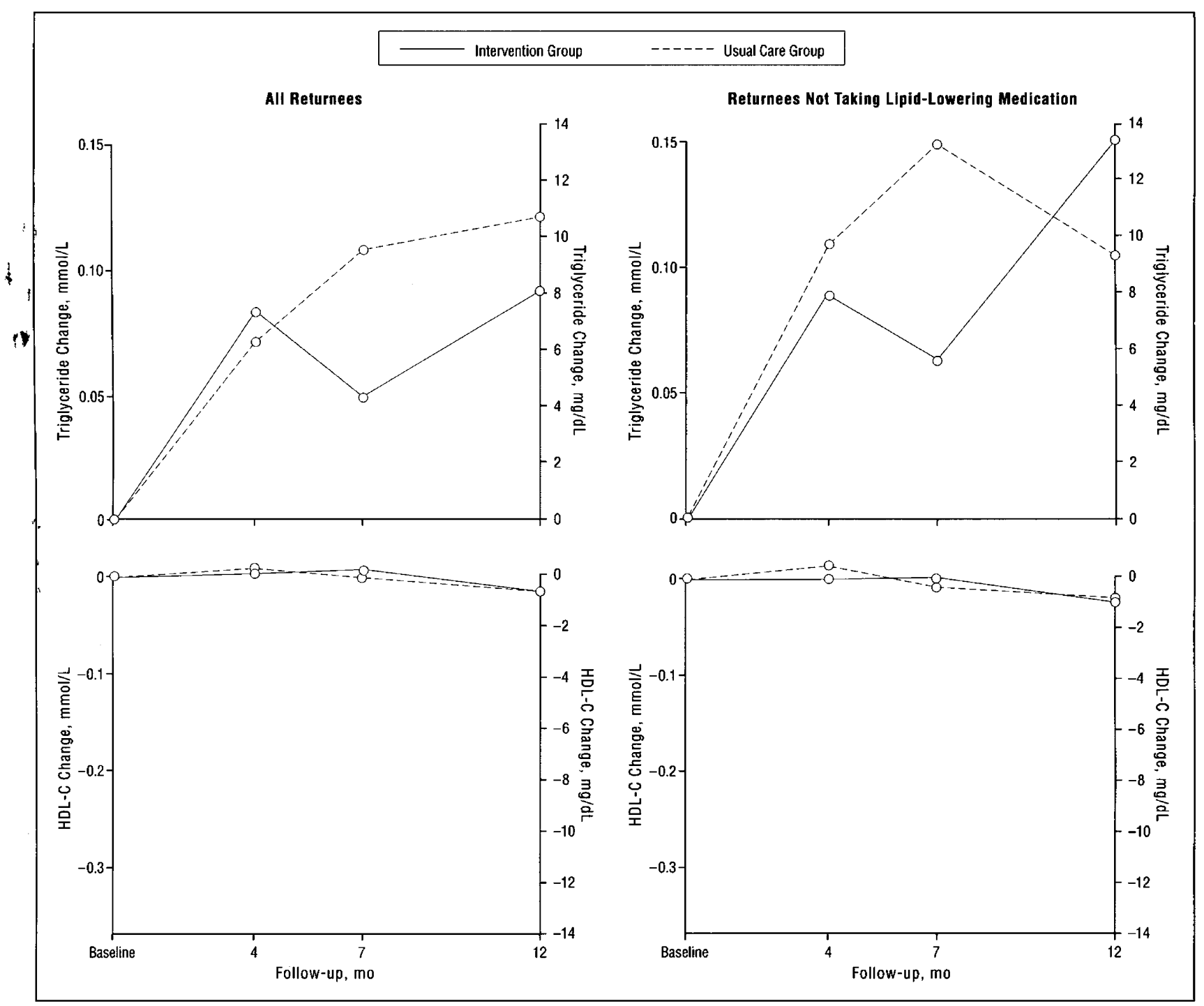

Figure 3. Adjusted mean changes from baseline in high-density lipoprotein cholesterol $(H D L-C)$ and triglycerides. Change in triglyceride values were calculated from non-log-transformed data.

was $0.14 \mathrm{mmol} / \mathrm{L}(5.5 \mathrm{mg} / \mathrm{dL})(95 \% \mathrm{CI}, 0.01$ to 0.28 $\mathrm{mmol} / \mathrm{L}$ [0.3 to $10.7 \mathrm{mg} / \mathrm{dL}])(P=.04)$; averaged over the l-year follow-up period, the difference was $0.14 \mathrm{mmol} / \mathrm{L}$ $(5.3 \mathrm{mg} / \mathrm{dL})(95 \% \mathrm{CI}, 0.03$ to $0.24 \mathrm{mmol} / \mathrm{L}$ [ 1.2 to 9.4 $\mathrm{mg} / \mathrm{dL})(P=.0 \mathrm{i})$. For LDL-C, the average reduction during the 1-year follow-up period was also $0.14 \mathrm{mmol} / \mathrm{L}$ ( 5.3 $\mathrm{mg} / \mathrm{dL})$ greater in the intervention group $(95 \% \mathrm{CI}, 0.03$ to $0.25 \mathrm{mmol} / \mathrm{L}$ [ 1.0 to $9.6 \mathrm{mg} / \mathrm{dL}$ ] $)(P=.02)$.

There was attenuation in total and LDL cholesterol reduction in both treatment groups from 4-month to 1-year follow-up (Table 3 and Figure 2). For all returnees, the attenuation in the reduction of total cholesterol from 4 months to l year of $0.07 \mathrm{mmol} / \mathrm{L}(2.9 \mathrm{mg} / \mathrm{dL})$ for intervention and $0.01 \mathrm{mmol} / \mathrm{L}(0.3 \mathrm{mg} / \mathrm{dL})$ for usual care was not statistically significant. Among intervention returnees who were not taking lipid-lowering medication, there was minimal change in cholesterol from 4 to 7 months and then a relatively large attenuation from 7 months to 1 year $(0.13 \mathrm{mmol} / \mathrm{L}$ [ $5.0 \mathrm{mg} / \mathrm{dL}$ ]; $95 \% \mathrm{CI}, 0.01$ to $0.25 \mathrm{mmol} / \mathrm{L}$ [ 0.5 to $9.6 \mathrm{mg} / \mathrm{dL}])$. The pattern of attenuation for LDL-C was similar.
Table 4 shows the change in self-reported dietary habits (DRA score) from baseline to follow-up and compares these changes between groups. There was a sustained decrease in this score in both treatment groups, with a significantly greater reduction in the intervention group. The average reduction for the intervention group was 3.3 more than for usual care $(95 \% \mathrm{CI}, 1.9$ to 4.8) $(P<.001)$.

\section{DEATHS}

During the l-year follow-up period, there were 2 deaths, both in the intervention group. Approximately 9 months after starting the study, a 60 -year-old man committed suicide. At enrollment, his values were as follows: baseline cholesterol, $5.82 \mathrm{mmol} / \mathrm{L}$ ( $225 \mathrm{mg} / \mathrm{dL}) ;$ HDL-C, 0.75 $\mathrm{mmol} / \mathrm{L}(29 \mathrm{mg} / \mathrm{dL})$; and LDL-C, $3.72 \mathrm{mmol} / \mathrm{L}$ (144 mg/ $\mathrm{dL}$ ). Five weeks before his death, he was not taking lipidlowering medication and his values were as follows: cholesterol, $5.59 \mathrm{mmol} / \mathrm{L}(216 \mathrm{mg} / \mathrm{dL}) ; \mathrm{HDL}-\mathrm{C}, 0.85 \mathrm{mmol} / \mathrm{L}$ (33 mg/dL); and LDL-C, $4.03 \mathrm{mmol} / \mathrm{L}(156 \mathrm{mg} / \mathrm{dL})$. Ap- 
Table 4. Reduction in Adjusted Mean Values for DRA Score From Baseline and Comparison of Change Between Groups*

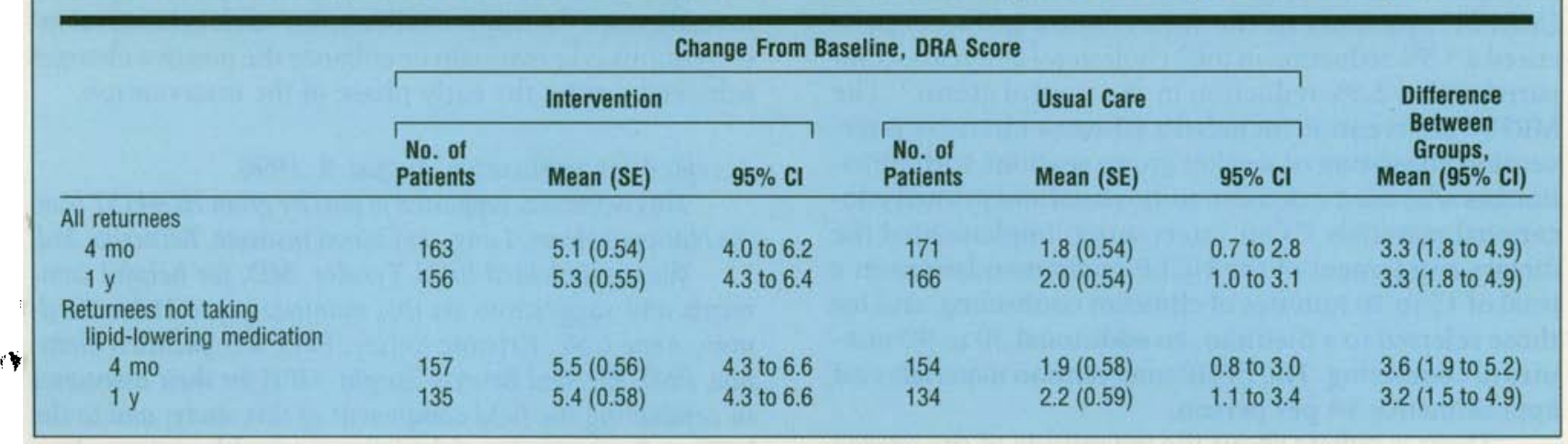

*Adjusted for following variables: age, sex, race, baseline dietary risk assessment (DRA) score, educational achievement, smoking, known coronary heart disease, marital status, total number of routine visits with clinicians, and diet counseling at these visits. A reduction in DRA score indicates an improved diet. $\mathrm{Cl}$ indicates confidence interval.

proximately 11 months into the study, a 62-year-old women died suddenly of natural causes (no autopsy or definitive diagnostic tests were done). At enrollment, her values were as follows: baseline cholesterol, $6.21 \mathrm{mmol} / \mathrm{L}$ $(240 \mathrm{mg} / \mathrm{dL}) ; \mathrm{HDL}-\mathrm{C}, 1.50 \mathrm{mmol} / \mathrm{L}(58 \mathrm{mg} / \mathrm{dL})$; and LDL-C, $4.03 \mathrm{mmol} / \mathrm{L}(156 \mathrm{mg} / \mathrm{dL})$. Three months before her death, she was not taking lipid-lowering medication and her values were as follows: cholesterol, 5.56 $\mathrm{mmol} / \mathrm{L}(215 \mathrm{mg} / \mathrm{dL}$ ); HDL-C, $1.27 \mathrm{mmol} / \mathrm{L}$ (49 mg/ $\mathrm{dL}$ ); and LDL-C, $3.78 \mathrm{mmol} / \mathrm{L}$ ( $146 \mathrm{mg} / \mathrm{dL}$ ). During a second year of follow-up, there were 3 additional deaths: a suicide in the usual-care group and 2 natural deaths in the intervention group.

\section{COMMINT}

Although guidelines for preventive clinical services are often published by "expert" panels, few of these recommendations are rigorously evaluated for feasibility or impact in randomized controlled trials conducted in routine primary care settings. ${ }^{32}$ Of particular concern is whether such guidelines will help clinicians reach underserved populations who are at greatest risk for CHD. In this study, we assessed the effectiveness of a cholesterol-lowering intervention that was designed to implement the NCEP recommendations in primary care practices serving lowincome patients. The intervention consisted of a brief clinician tutorial (1.5 hours), a modest amount of clinicianpatient contact (15-30 minutes total during 3 visits) for dietary counseling guided by a structured assessment and intervention package, and referral to a dietitian and prompt for lipid-lowering medication as indicated.

The effectiveness of the intervention was assessed by comparing changes in dietary intake and blood lipids during a l-year follow-up period. Compared with controls, intervention patients reported making significantly greater changes in their diets and experienced a greater reduction in total and LDL cholesterol that was of borderline statistical significance. A subgroup analysis excluding the small minority of patients who were taking lipid-lowering medication during follow-up ( $11 \%$ of returnees) demonstrated a statistically significant greater reduction in both total (2.1\%) and LDL cholesterol (2.9\%) for the intervention group compared with controls.
The observed difference in cholesterol reduction of $0.11 \mathrm{mmol} / \mathrm{L}(4.2 \mathrm{mg} / \mathrm{dL})$ between treatment groups at 4 months was less than the target goal of $0.39 \mathrm{mmol} / \mathrm{L}$ (15 mg/dL). This smaller-than-expected difference was attributable to successful cholesterol reduction in the usual-care group and a shortfall in the cholesterol reduction experienced by the intervention group. The phenomenon of desirable outcomes in control groups has been noted in several other clinical trials. ${ }^{33,34}$ In this trial, it was attributable at least in part to the efforts of usualcare clinicians to lower their patients' cholesterol, including frequent diet counseling at routine visits, early referrals to dietitians for counseling, and greater use of lipid-lowering medication compared with intervention clinicians. Moreover, the study protocol included multiple baseline and follow-up blood tests with results reported to clinicians and patients. These results may have served as significant prompts for both clinicians and patients to focus on cholesterol reduction.

Possible explanations for our failure to achieve greater cholesterol reduction in the intervention group include inadequate training and reinforcement for intervention clinicians on how to use the FFHP materials, insufficient clinician contact time with patients for counseling, dietary recommendations that were insufficiently stringent, or failure of the program to adequately motivate participants to achieve and maintain the recommended dietary changes. Furthermore, the fact that the majority of patients reported that they were trying to reduce their cholesterol by diet at the time of enrollment may have limited the lipid reduction that could be achieved by a dietary intervention, as important changes in consumption may have occurred before enrollment. . In this study, greater lipid reduction may have been achieved by a more rigorous training program for clinicians, more clinician-patient contact for counseling, greater involvement of other health providers, and a more systematic and rigorous maintenance component of the intervention for clinicians and patients.

Though modest, the absolute reduction in total and LDL cholesterol from baseline to follow-up was consistent with reports from other trials of cholesterollowering diets for individuals at high risk ${ }^{35,36}$ and were achieved with an intervention that used considerably fewer 
resources compared with many of the other trials. For example, in the Multiple Risk Factor Intervention Trial (MRFIT), patients in the intervention group experienced a $5.5 \%$ reduction in total cholesterol at 2 years, compared with a $2.5 \%$ reduction in the control group. ${ }^{33}$ The MRFIT intervention included a 10 -week intensive intervention consisting of weekly group sessions with nutritionists who used extensive audiovisual and printed educational materials.$^{37}$ Our intervention implemented the dietary component of the NCEP recommendations in a total of 15 to 30 minutes of clinician counseling, and for those referred to a dietitian, an additional 30 to $90 \mathrm{~min}-$

utes of counseling. The FFHP intervention materials cost approximately $\$ 4$ per person.

There is debate about the magnitude of the impact of lipid change both on CHD risk and on adverse medical outcomes. ${ }^{38}$ A recent meta-analysis by Law and colleagues, ${ }^{39}$ using data that adjust for regression dilution bias (random variation of cholesterol over time due to errors in measurement and within-person variation) and surrogate dilution affect (most observational studies measure total rather than LDL-C), suggests that a long-term reduction of total cholesterol by $10 \%$ lowers the risk of CHD by $54 \%$ if achieved at age 40 years and $20 \%$ if achieved at age 70 years. Given these estimates, the modest reductions in total and LDL cholesterol (4\% and 5\%, respectively) achieved in the intervention group at 1-year follow-up may be sufficiently large so that if maintained over time it would be associated with a reduction in the incidence of $\mathrm{CHD}$. Concerning the adverse medical outcomes of lowering blood cholesterol, recent reports suggest that these risks have been overstated ${ }^{40}$ or that they do not exist, except for a modest increased risk of hemorrhagic stroke associated with very low cholesterol levels. ${ }^{41}$

Intervention clinicians in this study were more likely to follow the NCEP recommendation of a 6-month diet therapy trial before prescribing lipid-lowering medication. In prior studies, physicians using the FFHP have shown increased confidence in their diet counseling ability (self-efficacy) and decreased skepticism about patient compliance, which may explain the greater willingness of intervention clinicians to give diet counseling a chance. ${ }^{42}$ Although we prompted intervention clinicians to consider lipid-lowering medication as appropriate after 6 months of diet therapy, the use of lipidlowering medication at 1 year was still less for the intervention group compared with the usual-care group (14\% vs 19\%). The majority of patients in both groups who met criteria for drug treatment were not taking lipidlowering medication, which may reflect a general reluctance on the part of physicians to commit their patients to lifelong and often expensive pharmacotherapy for hypercholesterolemia.

In conclusion, our intervention program designed to implement the NCEP guidelines resulted in improved dietary intake and a modest reduction in total and LDL cholesterol compared with the control group. Whether such changes in dietary habits and reductions in blood lipids will yield a decrease in CHD risk depends, in large part, on the maintenance of these changes over time. Given the observed attenuation in the reduc- tion of total and LDL cholesterol during our 1-year follow-up period and similar attenuation reported by other investigators, ${ }^{35}$ a major challenge for such behavioral interventions is to maintain or enhance the positive changes achieved during the early phase of the intervention.

Accepted for publication August 9, 1996.

This work was supported in part by grant HL44157 from the National Heart, Lung, and Blood Institute, Bethesda, Md. We are indebted to Al Tyroler, MD, for helpful comments and suggestions on this manuscript, to Helen Stedman, Anne Cole, Kristine Kelsey, PhD, RD, Jackilen Shannon, $P h D, R D$, and Beverly Turpin, MPH for their assistance in conducting the field component of this study, and to the staffs and participants at the following health centers, whose generous cooperation made this study possible: Boydton Medical Center, Boydton, Va; Brunswick Health Care (currently Alberta Family Health Services, a subsidiary of Central Virginia Health Services Inc), Brunswick, Va; Caswell Family Medical Center, Yanceyville, NC; Goshen Medical Center Inc: Goshen Medical Center, Faison, NC; and Plain View Health Services, Rose Hill, NC; Lunenburg Medical Center, Victoria, Va; Orange-Chatham Comprehensive Health Services (currently Piedmont Health Service): Carrboro Community Health Services, Carrboro, NC; Haywood-Moncure Community Health Center, Moncure, NC; and Prospect Hill Community Health Center, Prospect Hill, NC; Person Family Medical Center, Roxboro, NC; Roanoke-Amaranth Community Health Group: Roanoke-Amaranth Community Health, Jackson, NC; Rich Square Medical Center, Rich Square, NC; Twin County Rural Health Services, Hollister, NC; and Lake Gaston Medical Center, Littleton, NC; Robeson Health Care Corporation: Julian T. Pierce Health Center, Pembroke, NC; Maxton Medical Services, Maxton, NC; and South Robeson Medical Clinic, Fairmont, NC; Sandy River Medical Center, Axton, $\mathrm{Va}$; Vance-Warren Health Plan: HealthCo, Soul City, NC; and Warren Health Plan, Warrenton, NC; and Wake Health Services, Jones Street site, Raleigh, NC.

Corresponding author: Thomas C. Keyserling, MD, $\mathrm{MPH}$, Division of General Medicine and Clinical Epidemiology, University of North Carolina, Campus Box 7110 , Chapel Hill, NC 27599-7110.

\section{REIIRINCES}

1. The Expert Panel. Report of the National Cholesterol Education Program Expert Panel on Detection, Evaluation, and Treatment of High Blood Cholesterol in Adults. Arch Intern Med. 1988;148:36-69.

2. Feldman JJ, Makuc DM, Kleinman JC, Cornoni-Huntley J. National trends in . educational differentials in mortality. Am J Epidemiol. 1989;129:919-933.

3. Kaplan GA, Keil JE. Socioeconomic factors and cardiovascular disease: a review of the literature. Circulation. 1993;88:1973-1998.

4. Adams PF, Benson V. Current estimates from the National Health Interview Survey, 1991. Vital Health Stat 10. 1992; No. 181.

5. Zimmermann M, Kretchmer N. Isn't it time to teach nutrition to medical students? Am J Clin Nutr. 1993;58:828-829.

6. Winick M. Nutrition education in medical schools. Am J Clin Nutr. 1993;58: 825-827.

7. Schucker B, Wittes JT, Cutler JA, et al. Change in physician perspective on cholesterol and heart disease: results from two national surveys. JAMA. 1987; 258:3521-3526.

8. Giles WH, Anda RF, Jones DS, Serdula MK, Merritt RK, DeStefano F. Recent 
trends in the identification and treatment of high blood cholesterol by physicians: progress and missed opportunities. JAMA. 1993;269:1133-1138.

9. Counseling practices of primary-care physicians-North Carolina, 1991. MMWR Morb Mortal Wkly Rep. 1992;41:565-568.

10. Glanz K, Rudd J. Readability and content analysis of print cholesterol education materials. Patient Educ Counsel. 1990;16:109-118.

11. Kaufman $M$, Lee $S$. Nutrition services in state and local public health agencies: how do we measure up in 1987? J Am Diet Assoc. 1988;88:1576-1580.

12. Kottke TE, Foels JK, Hill C, Choi T, Fenderson DA. Nutrition counseling in private practice: attitudes and activities of family physicians. Prev Med. 1984;13: 219-225.

13. Jack BW, Gans KM, McQuade W, et al. A successful physician training program in cholesterol screening and management. Prev Med. 1991;20:364-377.

14. Beresford SAA, Farmer EMZ, Feingold L, Graves KL, Sumner SK, Baker RM. Evaluation of a self-help dietary intervention in a primary care setting. Am J Public Health. 1992;82:79-84.

15. Kottke TE, Blackburn H, Brekke ML, Solberg LI. The systematic practice of preventive cardiology. Am J Cardiol. 1987;59:690-694.

16. Kish L. Statistical Design for Research. New York, NY: John Wiley \& Sons Inc; 1987.

17. Meinert C. Clinical Trials: Design, Conduct, and Analysis. New York, NY: 0xford University Press; 1986.

18. Ammerman AS, DeVellis RF, Carey TS, et al. Physician-based diet counseling for cholesterol reduction: current practices, determinants, and strategies for improvement. Prev Med. 1993;22:96-109.

19. Green LW, Eriksen MP, Schor EL. Preventive practices by physicians: behavioral determinants and potential interventions. Am J Prev Med. 1988;4(suppl): 101-107.

20. Wechsler H, Levine S, Idelson RK, Rothman M, Taylor JO. The physician's role in health promotion: a survey of primary care practitioners. $N$ Eng/ J Med. 1983;308:97-100.

21. Zevallos JC, Ellison RC, Goldberg RJ, Green HL. Central Massachusetts physicians' practices and attitudes towards dietary counseling for high blood cholesterol. Clin Res. 1989;37:785A.

22. Ammerman AS, DeVellis BM, Haines PS, et al. Nutrition education for cardiovascular disease prevention among low-income populations: description and pilot evaluation of a physician-based model. Patient Educ Counsel. 1992;19:5-18.

23. Ammerman AS, Haines PS, DeVellis RF, et al. A brief dietary assessment to guide cholesterol reduction in low-income individuals: design and validation. J Am Diet Assoc. 1991;91:1385-1390.

24. Conner SL, Gustafson JR, Artaud-Wild SM, et al. The cholesterol/saturated fat index: an indication of the hypercholesterolaemic and atherogenic potential of food. Lancet. 1986;1:1229-1232.
25. Warnick GR, Benderson J, Albers JJ. Dextran sulfate- $\mathrm{Mg}^{2+}$ precipitation procedure for quantitation of high density-lipoprotein cholesterol. Clin Chem. 1982; 28:1379-1388.

26. Friedewald WT, Levy RI, Fredrickson DS. Estimation of the concentration of low-density lipoprotein cholesterol in plasma, without use of the preparative ultracentrifuge. Clin Chem. 1972;18:499-502.

27. Keys A, Anderson J, Grande F. Serum cholesterol in man, diet, fat and intrinsic responsiveness. Circulation. 1959;19:201-214.

28. Binder DA. On the variance of asymptotically normal estimators from complex surveys. Int Stat Rev. 1983;51:279-292.

29. Stata Corp. Stata Statistical Software, Release 4.0. College Station, Tex: Stata Corp; 1995.

30. Bryk AS, Raudenbush SW. Hierarchical Linear Models. Newbury Park, Calif: Sage Publications; 1992.

31. SAS Institute Inc. SAS/STAT Software: Changes and Enhancements, Release 6.07. Cary, NC: SAS Institute Inc; 1992.

32. Ammerman A, Caggiula A, Elmer PJ, et al. Putting medical practice guidelines into practice: the cholesterol model. Am J Prev Med. 1994;10:209-216.

33. Neaton JD, Broste S, Cohen L, Fishman EL, Kjelsberg MO, Schoenberger J. The Multiple Risk Factor Intervention Trial (MRFIT), VII: a comparison of risk factor changes between the two study groups. Prev Med. 1981;10:519543.

34. Writing Group for the DISC Collaborative Research Group. Efficacy and safety of lowering dietary intake of fat and cholesterol in children with elevated lowdensity lipoprotein cholesterol. JAMA. 1995;273:1429-1435.

35. Denke MA. Cholesterol-lowering diets: a review of the evidence. Arch Intern Med. 1995;155:17-26.

36. Caggiula AW, Watson JE, Kuller LH, et al. Cholesterol-lowering intervention program: effect of Step I diet in community office practices. Arch Intern Med. 1996;156:1205-1213.

37. Caggiula AW, Christakis G, Farrand $M$. The Multiple Risk Factor Intervention Trial (MRFIT), IV: intervention on blood lipids. Prev Med. 1981;10:443-475.

38. Marmot M. The cholesterol papers. BMJ. 1994;308:351-352.

39. Law MR, Wald NJ, Thompson SG. By how much and how quickly does reduction in serum cholesterol concentration lower risk of ischaemic heart disease? BMJ. 1994;308:367-372.

40. Thompson SG. Controversies in meta-analysis: the case of the trials of serum cholesterol reduction. Stat Methods Med Res. 1993;2:173-192.

41. Law MR, Thompson SG, Wald NJ. Assessing possible hazards of reducing serum cholesterol. BMJ. 1994;308:373-379.

42. Ammerman A, Carey T, DeVellis R, et al. A physician-based dietary intervention to reduce cholesterol. Circulation. 1990;82:III-59. 